\title{
BILATERAL THELORRHAGIA IN A 22-MONTHS-OLD BOY
}

José David Martinez Pajares, Olga Diaz Morales, Juan Carlos Ramos Diaz Unidad de Pediatría. Hospital de Antequera. Area Sanitaria Norte de Málaga

\section{BACKGROUND AND AIMS}

Breast conditions are not frequent complaints in children, being physiological mammary hypertrophy and milky secretion in infants the most common problems found. However, bloody nipple discharge is a rare symptom in this age.

\section{METHOD}

Case Report.

\section{RESULTS}

A 22-months-old boy with unremarkable personal and familial history presents with a sudden onset bilateral bloody nipple discharge. The mother did not refer any previous traumatism, handling or eczema. The clinical condition was excellent, without fever or other systemic symptoms, and both breasts were normal, with no pain, redness or tender. No masses or wounds were objectivated. A soft pressure provoked a painful bleeding discharge in both nipples. Complementary test as blood count, coagulation tests and ultrasonography were normal, and the histological examination of blood sample only shows histiocytes and ductal epithelial cells. These findings were consistent with benign ductal ectasia.

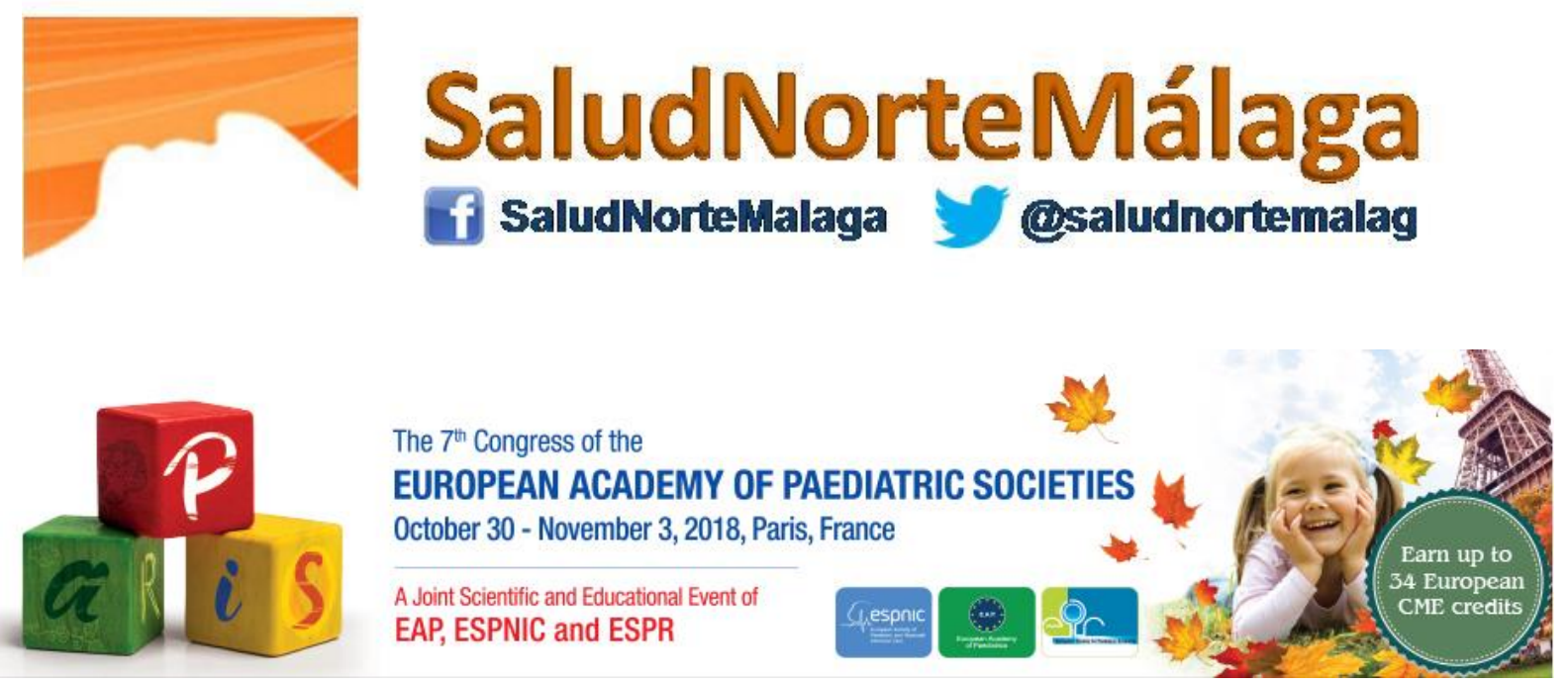

A bloody nipple discharge in adult population is associated to both benign ang malign process, as ductal papilloma, breast neoplasia or ductal ectasia. In children, benign ductal ectasia is considered the most frequent cause of thelorrhagia. The aetiology of this rare condition is unknown, but bleeding occurs after milky ducts dilatation, and can involve one or both breasts. The clinical features described here are similar that those seen in the literature. Diagnosis can be done after clinical exam and resolves in a few weeks or months with a conservative management. In conclusion, although a bloody nipple discharge in children can be a threatening symptom, the underlying condition is benign and self-limited.

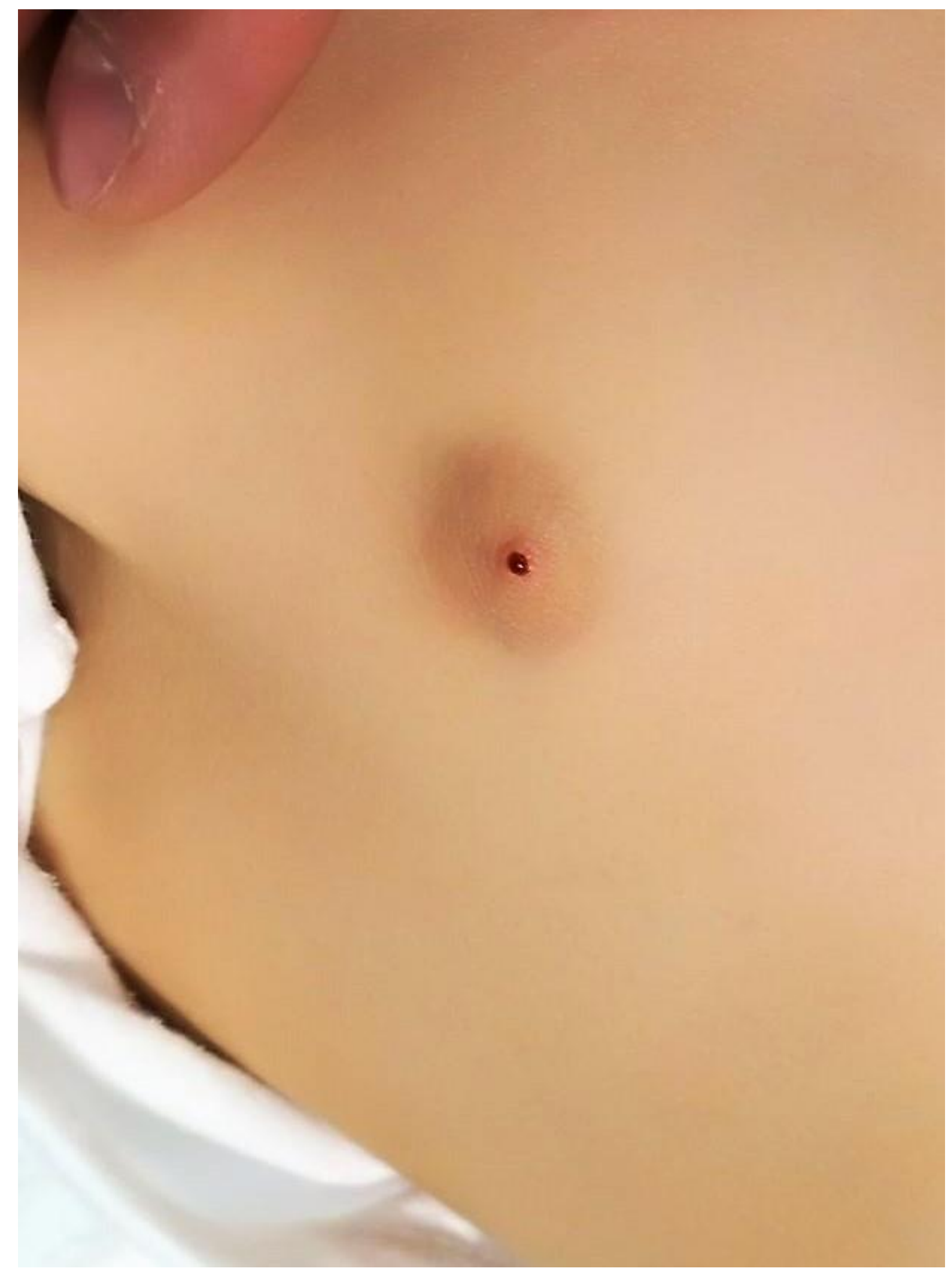

